\title{
Pemodelan Risiko Investasi di Indonesia
}

\author{
Muhammad Adnan ${ }^{1 *}$, Zurriyani ${ }^{2}$ \\ 1,2 Fakultas Ekonomi dan Bisnis Islam, Universitas Islam Negeri Ar-raniry, \\ Kota Banda Aceh, Provinsi Aceh, Indonesia.
}

\begin{abstract}
Abstrak. Penelitian ini bertujuan untuk menganalisis pengarub interaksi faktor internal dan eksternal dengan indek pasar modal global terbadap return IHSG di Indonesia. Menggunakan data runtut waktu (time series) triwulan periode tabun 2004-2018, model analisis yang digunakan terdiri dari uji kointegrasi dan vector error correction model (VECM). Penelitian menemukan adanya bubungan kointegrasi antar variabel yang diteliti. Baik dalam jangka panjang maupun jangka pendek, return MSCI ACWI IMI tidak berpengaruh signifikan terhadap return IHSG di Indonesia.
\end{abstract}

Kata kunci: Return IHSG; Indek Pasar Modal Global; Uji Kointegrasi; VECM.

\begin{abstract}
This study aims to analyze the effect of the interaction of internal and external factors with the global capital market index on IHSG returns in Indonesia. Using quarterly time series data for the period 2004-2018, the analytical model used consists of a cointegration test and a vector error correction model (VECM). The study found a cointegration relationship between the variables studied. Both in the long term and in the short term, the return on the MSCI ACWI IMI has no significant effect on the return on the IHSG in Indonesia.
\end{abstract}

Keywords: IHSG Returns; Global Capital Markets Index; Cointegration Test; VECM. 


\section{Pendahuluan}

Perkembangan perekonomian suatu negara tidak terlepas dari keberadaan pasar modal yang dipandang sebagai sarana yang efektif untuk mempercepat pembangunan suatu negara. Pasar modal merupakan barometer dari kondisi perekonomian suatu negara sehingga pasar modal disebut juga sebagai salah satu indikator utama perekonomian negara. Pasar modal merupakan salah satu perantara keuangan yang keradaannya dapat berdampak pada pertumbuhan ekonomi (McKinnon, 1973; Shaw; 1973).

Krisis keuangan global (2008) dan krisis hutang yang terjadi di benua Eropa (2010) berpengaruh terhadap pasar modal dibeberapa negara termasuk pasar modal Indonesia dan berpotensi dapat menimbulkan risiko sistematis. Return Morgan Stanley Capital International (MSCI), All Country World Index (ACWI) dan Investable Market Index (IMI) yang merupakan benchmark pasar modal dunia juga mengalami penurunan performance pada tahun 2008 sebesar $-42.01 \%$.

Kajian mengenai determinan risiko investasi di pasar modal telah dilakukan oleh sejumlah peneliti. Kajian Vij \& Kapoor (2007) membuktikan bahwa indikator makroekonomi yang memengaruhi country risk yaitu GNP, current account balance/GNP, dan external debt repayment/GNP. Sedangkan Topak dan Muzir (2011) menyatakan bahwa wholesale price index sebagai indikator inflasi, open market operation, market interest rate berhubungan positif dengan country risk. Real exchange rate index, domestic assets, foreign debts, reserve, consumer confident index, wage index, employment index, GDP dan issue volume berhubungan negatif dengan country risk.

Berbeda dengan kedua peneliti tersebut, penelitian ini menggunakan sejumlah variabel makro ekonomi untuk memprediksi country risk beta di Indonesia. Penelitian ini fokus berusaha untuk mengembangkan country beta approach yang diperkenalkan oleh Harvey (1991) dimana model ini telah digunakan oleh beberapa peneliti sebelumnya baik di emerging market dan developed market. Penelitian ini menggunakan indeks pasar global yaitu Morgan Stanley Capital International (MSCI), All Country World Index
(ACWI) dan Investable Market Index (IMI) untuk mengukur return portofolio investasi global. Indeks pasar global digunakan dalam penelitian ini disebabkan oleh adanya saling ketergantungan dan hubungan dinamis serta semakin terintegrasinya antar satu bursa saham dengan bursa saham lainnya. Selain itu, penelitian ini juga menggunakan time varying beta. Menurut Bos \& Newold (1984), Collins, Ledolter dan Rayburn (1984) dalam Tandelilin (2010: 548-549) beta saham individual dan beta portofolio adalah time varying. Adanya variasi waktu dalam beta tersebut disebabkan oleh perubahan situasi perusahaan dan kondisi pasar. Jaganathan dan Wang (1996), Akdeniz et al. (2002) menyatakan bahwa variasi beta dan expected return tergantung pada informasi dari isu-isu spesifik yang berasal dari perusahaan dan kondisi perekonomian saat itu. Berdasarkan beberapa pertimbangan di atas, maka penelitian ini menjadi penting untuk dilakukan sehingga dapat menjawab fenomena bisnis dan empiris investasi di Indonesia. Secara spesifik penelitian ini menganalisis pengaruh interaksi faktor internal dan eksternal dengan MSCI, ACWI, dan IMI terhadap return IHSG di Indonesia.

\section{Tinjauan Literatur}

Investasi merupakan konsumsi yang ditunda sementara waktu untuk dikonsumsikan lebih besar dimasa mendatang (Brealey \& Myers, 2000). Investasi portofolio sebagai alokasi kekayaan yang tersisa (remaining wealth) untuk aset keuangan dan aset riil dengan tujuan untuk memaksimalkan return yang diharapkan dari kekayaan tersebut (Batram \& Dufey, 2001). Investasi di pasar modal tidak terlepas dari risiko sehingga investor dihadapkan pada ketidakpastian pengembalian investasi yang akan mereka peroleh. Salah satu risiko dimaksud adalah risiko sistematis atau risiko pasar merupakan risiko yang timbul akibat dari kejadian-kejadian di luar perusahaan seperti: perubahan sistem pemerintahan, bencana alam, perubahan makroekonomi, politik, hukum, sosial, budaya dan teknologi. Risiko sistematis dapat diukur dengan beta $(\beta)$.

Menurut Sharpe (1964) dan Lintner (1965) beta merupakan focal point dari investasi dan keputusan pembiayaan. Beta merupakan parameter risiko sistematis suatu sekuritas yang 
tidak dapat dihilangkan dengan melakukan diversifikasi. Selain itu, Beta menunjukkan sensitivitas return sekuritas terhadap perubahan return pasar. Semakin tinggi beta suatu sekuritas maka semakin sensitif sekuritas tersebut terhadap perubahan pasar. Sebagai ukuran sensitivitas return saham, beta dapat juga digunakan untuk membandingkan risiko sistematis antara satu saham dengan saham lainnya. Dalam model keseimbangan CAPM, nilai beta sangat memengaruhi tingkat keuntungan yang diharapkan pada suatu sekuritas. Semakin tinggi nilai beta dan return pasar maka akan semakin tinggi tingkat return yang disyaratkan oleh investor.

Gangemi et al. (2000) menyatakan bahwa country risk beta merupakan fungsi ekposure suatu negara terhadap pasar dunia. Menurut Esch et al. (2005) country risk beta adalah risiko sistematis dari portofolio suatu investasi dan risiko tersebut sangat sulit untuk dieliminasi dengan diversifikasi. Verma \& Soydemir (2006) menambahkan bahwa country risk beta merupakan risiko yang muncul akibat investor melakukan investasi internasional, risiko ini merupakan risiko tidak sistematis (unique risk) jika mengacu dari sisi investor asing yang melakukan investasi di negara lain, namun jika dilihat dari investor domestik risiko ini merupakan risiko sistematis. Berdasarkan berbagai definisi di atas, maka dapat disimpulkan bahwa konsep beta atau country risk beta merupakan risiko sistematis $(\beta)$ dimana risiko ini muncul ketika investor melakukan investasi di negara berbeda atau melakukan diversifikasi internasional. Selama ini penelitian yang telah dilakukan hanya melihat bagaimana pengaruh strategi investasi global terhadap country risk beta suatu negara terutama negaranegara emerging market, hal ini disebabkan investor di emerging market sangat terbatas memperoleh informasi besarnya risiko yang akan diterima jika melakukan investasi di emerging market. Hasil penelitian terhadap country risk suatu negara selalu berbeda-beda, karena variabel makroekonomi yang relevan antara developed market dan emerging market berbeda.

Penelitian empiris Harvey (1991) menilai country risk sebagai syarat sensitivitas (covariance) dari return suatu negara terhadap return pasar modal dunia. Harvey \& Zhou (1993) melakukan estimasi country beta 17 (tujuh belas) negara berkembang atas efek dari suatu portofolio pasar dunia. Harvey menghitung country risk dengan menggunakan koefisien beta yang ditunjukkan dengan data parameter time-varying dan hal ini merupakan fungsi dari sejumlah varibel independen ekonomi dan finansial. Studi yang dilakukan Gangemi et al. (2000) menggunakan model country beta untuk menganalisis dampak variabel makroekonomi dan fokus pada open economy variables. Temuannya adalah bahwa nilai tukar merupakan salah satu faktor yang signifikan memengaruhi country beta di Australia. Andrade \& Teles (2004) melakukan penelitian country risk Brazil dengan menggunakan model country beta. Mereka menganalisis dampak variabel makroekonomi terhadap country risk Brazil dengan suatu pendekatan parameter time-varying. Hasil penelitian mereka mengatakan bahwa country risk Brazil secara signifikan dipengaruhi oleh kebijakan moneter yang stabil.

\section{Metodologi Penelitian}

Penelitian ini merupakan penelitian kuantitatif yang tergolong dalam penelitian ekplanasi yaitu suatu penelitian yang berusaha untuk menjelaskan pengaruh variabel-variabel yang diteliti melalui pengujian hipotesis (Anshori \& Iswati, 2009: 12). Penelitian ini menguji dan menganalisis pengaruh interaksi faktor internal dan faktor eksternal dengan return MSCI ACWI IMI terhadap return Indeks Harga Saham Gabungan (IHSG). Data yang digunakan adalah data runtut waktu (time series) triwulan periode tahun 2004-2018. Data nilai tukar Rupiah terhadap US\$ dan BI rate diperoleh dari Bank Indonesia (BI). Data inflasi dan pertumbuhan ekonomi Indonesia diperoleh dari Biro Pusat Statistik (BPS). Data harga minyak dunia, Fed Fund Rate dan pertumbuhan ekonomi Amerika diperoleh dari International Financial Statistics (IFS). Data Indeks Harga Saham Gabungan (IHSG) diperoleh dari Bursa Efek Indonesia. Data MSCI ACWI IMI diperoleh dari www.msci.com. Selanjutnya model analisis yang digunakan adalah uji kointegrasi dan vector error correction model. 


\section{Hasil dan Pembahasan}

\section{Hasil Uji Kointegrasi}

Uji kointegrasi dilakukan untuk mendeteksi adanya hubungan jangka panjang antar variabel (Amri \& Aimon, 2017; Amri \& Nazamuddin, 2018). Uji kointegrasi yang digunakan adalah Johansen contegration test yang telah tersedia dalam program EViews berdasarkan lag optimal. Uji Johansen ini dilakukan dengan dua statistik, yaitu maximum-eigen test. Dalam hal ini, jika statistik trace test maupun maximum-eigen test bernilai lebih besat dari critical value 0,05, ini berarti terdapat hubungan kointegrasi antara variabel yang dianalisis (Amri, 2019; Ikhsan et al., 2020). Hasil uji kointegrasi seperti ditunjukkan dalam Tabel 1.

Tabel 1. Hasil Uji Kointegrasi

\begin{tabular}{|c|c|c|c|c|}
\hline $\begin{array}{l}\text { Hypothesized } \\
\text { No. of CE(s) }\end{array}$ & $\begin{array}{l}\text { Eigen } \\
\text { value }\end{array}$ & $\begin{array}{l}\text { Max } \\
\text { Eigen } \\
\text { Statistic }\end{array}$ & $\begin{array}{l}\text { Critical } \\
\text { Value }\end{array}$ & Prob.** \\
\hline None $*$ & 0.971 & 134.585 & 68.812 & 0.000 \\
\hline At most 1 $*$ & 0.922 & 97.063 & 62.752 & 0.000 \\
\hline At most 2 $*$ & 0.846 & 71.035 & 56.705 & 0.001 \\
\hline At most 3 $*$ & 0.745 & 51.899 & 50.599 & 0.034 \\
\hline At most 4 & 0.595 & 34.340 & 44.497 & 0.405 \\
\hline At most 5 & 0.515 & 27.486 & 38.331 & 0.492 \\
\hline At most 6 & 0.344 & 16.029 & 32.118 & 0.909 \\
\hline At most 7 & 0.297 & 13.404 & 25.823 & 0.772 \\
\hline At most 8 & 0.256 & 11.258 & 19.387 & 0.487 \\
\hline
\end{tabular}

Sumber: Hasil Data Olahan dengan EViews 8

* berarti nilai Max-Eigen Statistic $>$ Critical V alue $(0,05)$

Berdasarkan hasil uji kointegrasi, terlihat bahwa nilai Trace statistic dan Max-Eigen lebih besar dari nilai kritis 0,05 , sehingga dapat disimpulkan bahwa data tersebut terkointegrasi. Hal ini menunjukkan behwa terdapat hubungan jangka panjang antara variabel yang digunakan dalam penelitian ini terhadap return IHSG. Terkointegrasinya suatu data menunjukkan sinyal yang tepat untuk menggunakan metode VECM dan selanjutnya dapat menentukan estimasi VECM.

\section{Analisis Vector Error Correction Model (VECM)}

Hasil estimasi dengan VECM diperoleh koefisien jangka panjang dan jangka pendek. Berikut ini ditunjukkan hasil estimasi VECM jangka panjang yaitu:
Tabel 2. Hasil Estimasi Vecm Jangka Panjang

\begin{tabular}{|c|c|}
\hline Cointegrating Eq: & CointEq1 \\
\hline RETURNIHSG(-1) & 1.000 \\
\hline RETURNMSCI(-1) & -6.179 \\
\hline & {$[-1.481]$} \\
\hline BIRATEMSCI(-1) & -0.327 \\
\hline & {$[-1.211]$} \\
\hline INFLASIMSCI(-1) & 0.019 \\
\hline & {$[0.184]$} \\
\hline GROWTHINDOMSCI(-1) & -1.062 \\
\hline & {$[-3.032]^{*}$} \\
\hline KURSMSCI(-1) & 0.001 \\
\hline & {$[3.082]^{*}$} \\
\hline FEDMSCI(-1) & 0.646 \\
\hline & {$[3.606]^{*}$} \\
\hline OILMSCI(-1) & 0.059 \\
\hline & {$[7.429]^{*}$} \\
\hline GROWTHUSAMSCI(-1) & 0.665 \\
\hline & {$[7.208]^{*}$} \\
\hline $\mathrm{C}$ & -0.036 \\
\hline
\end{tabular}

Sumber: Hasil Data Olahan dengan E-Views 8

Keterangan: [ ] = t- statistik, $*$ berarti signifikan pada nilai $\alpha$ $=5 \%$.

Hasil estimasi VECM jangka panjang menunjukkan bahwa variable return MSCI, interaksi BI rate dengan return MSCI, interaksi pertumbuhan ekonomi Indonesia dengan return MSCI berpengaruh negatif terhadap country risk beta dan return IHSG. Artinya jika variabel tersebut di atas naik sebesar satu unit satuan maka country risk beta dan return IHSG akan turun sebesar 1,062 satu satuan.

Variabel interaksi inflasi dengan return MSCI, interaksi FED fund rate dengan return MSCI, interaksi harga minyak dunia dengan return MSCI, interaksi pertumbuhan Amerika Serikat ekonomi dengan return MSCI berpengaruh positif terhadap country risk beta dan return IHSG. Artinya, jika variabel tersebut naik satu satuan maka country risk beta meningkat sebesar persentase dari koefisien masing-masing variabel, atau dapat dijelaskan bahwa ketika 
Kurs meningkat 1 USD maka country risk beta dan return IHSG akan meningkat 0.001 satu satuan. Berikut ini ditunjukkan hasil estimasi VECM jangka pendek yaitu sebagai berikut:

Tabel 3. Hasil Estimasi Jangka Pendek

\begin{tabular}{|c|c|}
\hline Error Correction & D(Return IHSG) \\
\hline CointEq1 & 0.254 \\
\hline D(RETURNIHSG(-1)) & -0.646 \\
\hline & {$[-2.213]^{*}$} \\
\hline D(RETURNMSCI(-1)) & -6.225 \\
\hline & {$[-1.354]$} \\
\hline D(BIRATEMSCI(-1)) & -0.393 \\
\hline & {$[-0.997]$} \\
\hline D(INFLASIMSCI(-1)) & 0.234 \\
\hline & {$[1.477]$} \\
\hline D(GROWTHINDOMSCI(- & 1.049 \\
\hline & {$[2.088]^{*}$} \\
\hline $\mathrm{D}$ (KURSMSCI $(-1))$ & 0.001 \\
\hline & [1.449] \\
\hline $\mathrm{D}($ FEDMSCI$(-1))$ & 0.279 \\
\hline & [1.539] \\
\hline D(OILMSCI(-1)) & 0.005 \\
\hline & {$[0.484]$} \\
\hline $\begin{array}{c}\text { D(GROWTHUSAMSCI(- } \\
1) \text { ) }\end{array}$ & -0.394 \\
\hline & {$[-2.903]^{*}$} \\
\hline
\end{tabular}

Sumber: Hasil Data Olahan dengan E-Views

Keterangan: [ ] = t- statistik dan tanda $*$ berarti signifikan pada nilai $\alpha=5 \%$.

Persamaan model di atas menunjukkan bahwa untuk jangka pendek return IHSG, return MSCI, interaksi BI rate dengan return MSCI dan interaksi pertumbuhan ekonomi Amerika Serikat dengan return MSCI berpengaruah negatif terhadap country risk beta dan return IHSG. Interaksi inflasi dengan return MSCI, Interaksi pertumbuhan ekonomi Indonesia dengan return MSCI, Interaksi kurs dengan return MSCI, interaksi FED dengan return MSCI dan interaksi harga minyak dunia dengan return MSCI berpengaruh positif terhadap country risk beta dan return IHSG. Adanya kointegrasi antara variabel dependen dan variabel independen atau keseimbangan jangka panjang, memungkinkan terjadi ketidakseimbangan untuk jangka pendek. Ketidakseimbangan ini sering dijumpai dalam perilaku ekonomi, yang berarti apa yang diinginkan pelaku ekonomi belum tentu sama dengan apa yang terjadi sebenarnya, sehingga adanya perbedaan tersebut diperlukan penyesuaian (adjusment). Model yang memasukkan penyesuaian untuk koreksi bagi keseimbangan disebut model koreksi kesalahan (Error Correction Model = ECM). Menurut Gujarti dan Porter (2012: 458) koefisien speed of adjustment bernilai nol sampai satu. Berdasarkan hasil estimasi VECM jangka pendek diketahui nilai Error Correction Term (ECT) sebesar 0.254, nilai tersebut menunjukkan bahwa disequilibrium sebelumnya terkoreksi pada periode sekarang sebesar $0.254 \%$. ECT menunjukkan seberapa cepat ketidakseimbangan kembali ke dalam keseimbangan jangka panjang.

\section{Kesimpulan}

Berdasarkan analisis studi dan pembahasan sebelumnya, maka dapat ditarik kesimpulan bahwa dalam jangka panjang maupun jangka pendek return MSCI ACWI IMI tidak berpengaruh signifikan terhadap country risk beta. MSCI ACWI IMI yang merupakan benchmark indeks pasar global memengaruhi country risk beta, hal ini menunjukkan bahwa pasar modal Indonesia tidak memiliki keterkaitan erat dengan pasar saham negara lain. Investor yang melakukan investasi di Indonesia tidak terpengaruh oleh return pasar modal global. Interaksi suku bunga BI rate dengan return MSCI ACWI IMI tidak berpengaruh signifikan terhadap country risk beta. Sebaliknya, interaksi nilai tukar Rupiah atas USD dengan return MSCI ACWI IMI untuk jangka panjang berpengaruh positif dan signifikan

Dalam jangka pendek, kurs tidak berpengaruh terhadap country risk beta. Dalam jangka panjang fluktuasi nilai tukar rupiah terhadap US\$ akan direspon dengan cepat oleh pelaku pasar saham di Bursa Efek Indonesia dengan menjualnya saham yang dimilikinya dan beralih ke USD, sehingga menyebabkan indeks harga saham menjadi turun dan akan memengaruhi 
keputusan investor untuk melakukan investasi di Bursa Efek Indonesia. Selanjutnya, tnteraksi inflasi dengan return MSCI ACWI IMI untuk jangka panjang dan jangka pendek tidak berpengaruh signifikan terhadap country risk beta.

Mengacu pada kesimpulan di atas, maka penelitian ini memiliki implikasi bahwa investor harus mempertimbangkan sejumlah faktor ketika melakukan investasi di pasar modal, terutama faktor-faktor yang berkaitan dengan indikator makro ekonomi seperti inflasi dan nilai tukar rupiah terhadap US\$.

\section{Daftar Pustaka}

Akdeniz, L., Ashhan, A.S., \& Mehmet, C. (2002). Time-varying beta help in asset pricing: The threshold CAPM. Econpapers:

Http://EconPapers.repec.org/RePEc.

Amri, K. (2019). Apakah infrastruktur jalan mempengaruhi ekspor? Pendekatan vector utoregressive. Inovbir: Jurnal Inovasi Bisnis, 7 (2), 166-173.

Amri, K., \& Aimon, H. (2017). Pengaruh pembentukan modal dan ekspor terhadap pertumbuhan ekonomi Indonesia. Economac: Jurnal Ilmiah Ilmu Ekonomi, 1 (1), 1-16.

Amri, K.., \& Nazamuddin. (2018). Is there causality relationship between export and employment: A time series data evidence from Indonesia. International Journal of Academic Research in Economics and Management Sciences, 7(2), 86-99.

Andrade, J.P., \& Teles, V. K. (2006). An empirical model of the brazilian country risk - An extension of the beta country risk model. Applied Economics, 38, 12711278.

Anshori, M., \& Sri, I. (2009). Metodologi Penelitian Kuantitatif. Edisi Pertama, Surabaya: Airlangga University Press.
Brealey, R.A., \& Myers, S.C. (2001). Principles of Corporate Finance. $4^{\text {th }}$ Edition. New York: McGraw-Hill Companies.

Esch, C. B., Harvey, C. R., \& Viskanta, T. E. (2005). Country risk and global equity selection. Journal of Portfolio Management, Winter: 74-83.

Gangemi, M.A.M., Brooks R.D., \& Faff, R.W. (2000). Modeling Australia's country risk: A Country beta approach. Journal of Economics and Business, 52: 259-276.

Harvey, C. R., \& Zhou, G. (1993). International asset pricing with alternative distributional specifications. Journal of Empirical Finance, 1: 107-131.

Ikhsan, Fitri, C. D., Maulana, H., \& Amri, K. (2020). Effect of inflation on total deposits and financing of sharia commercial banks: A monthly data evidence from Indonesia. Regional Science Inquiry, 12 (1), 103-114

Lintner, J. (1965). The valuation of risk assets and the selections of risky investments in stock portfolio and capital budgets. Review of Economics and Statistic, 47: 13-37.

McKinnon, R. (1973). Money and Capital in Economic Development. Brooking Institution Washington, D.C.

Sharpe, W. (1964). Capital asset price: A theory of market equilibrium under conditions of risk. Journal of Finance, 19: 425-442.

Shaw, E.S. (1973). Financial deepening in economic development. New York: Oxford University Press.

Tandelilin, Eduardus. (2010). Portofolio dan investasi. Edisi Pertama. Yogjakarta: Penerbit Kanisius.

Verma, R., \& Soydemir, G. (2006). Modeling country risk in Latin America: A country beta approach. Global Finance Journal, 17: 192-213. 
Vij, Madhu \& M.C., Kapoor. (2007). Country risk analysis: A Case study of India. Journal of Management Research, 7(2): 87102.
Wang, J. (1996). The impact of foreign ownership on stock volatility in Indonesia. Financial Research Network (FIRN), University of Technology Sydney, March 